\title{
LAS PERCEPCIONES Y EXPECTATIVAS TURÍSTICAS A PARTIR DE UNA PELÍCULA ANIMADA. EL CASO DE RÍO
}

Santiago Salinas

Judith García

Universidad Técnica Particular de Loja

dssalinas1@utpl.edu.ec

judith.garcia@upec.edu.ec

Material original autorizado para su primera publicación en la revista académica REDMARKA. Revista Digital de Marketing Aplicado.

https://doi.org/10.17979/redma.2017.02.019.4854

Recibido: 27 Septiembre 2017

Aceptado: 04 Diciembre 2017

\section{Resumen}

Dentro de las tendencias post-modernas, el turismo cinematográfico concita el interés de los actores turísticos (Kim, S. 2012; Beeton, S. 2005; Connell J. 2012; Croy G. 2010; Roesch, 2009; Seaton, P. y Yamamura, T. 2015). Desde la perspectiva de género y tipo de film, las películas animadas no han sido consideradas a pesar de evidentes similitudes con las no animadas. Además, existen asociaciones entre audiencias, películas, percepciones y la gestión turística, debido al efecto de las mismas en términos de emociones, valores de producción, género cinematográfico y destinos. También, por el gran potencial en relación a la penetración de mercado, acceso, consumo de producciones cinematográficas y desarrollo de productos turísticos innovadores.

El presente estudio explora el impacto del film animado Rio en las percepciones y expectativas turísticas, donde potenciales turistas sin previa experiencia en turismo en Rio de Janeiro, fueron entrevistados antes y después de ver el film. Las particularidades generales de las películas animadas fueron estimadas como influyentes en los impactos generales en percepciones, pero no fueron evaluadas. Finalmente el estudio propone y pone a prueba una metodología alternativa cualitativa y cuantitativa que puede ser replicada con otras películas animadas que retraten otros destinos y además sugiere enfoques cuantitativos más elaborados. 
Palabras clave: turismo cinematográfico, percepciones y expectativas, imagen de destino.

\begin{abstract}
Within the post-modern tourism trends, increases the interest of tourist representatives on the subject of film tourism, from the perspective of gender and type of film, however; animated films have not been considered despite obvious similarities with non-animated films. There are associations in the audience, between films and perceptions as well as in tourism management, due to the effect in terms of emotions, values of production, gender and type of film, and above all; films have great potential in regard to consumption, access and market introduction.

This study explores the impact of animated film River in tourist perceptions and expectations, where potential tourists without prior experience in Rio de Janeiro were interviewed before and after enjoying the animated film. The animated film was influential in general perceptions but impact was not measured. Finally, the study proposes and tests a qualitative alternative methodology to be replicated with other animated films that portray other destinations and suggests quantitative approaches.
\end{abstract}

Key words: film tourism, perceptions and expectations, target image. 


\section{Introducción}

El presente estudio examina los impactos en las percepciones y expectativas turísticas que surgen de una experiencia cinematográfica. Investigaciones sobre películas que influyen en la imagen de un destino han sido realizadas previamente, pero se ha identificado una brecha en cuanto a las películas animadas a pesar de que estas comparten similares características que las no animadas, especialmente en cuanto a su permeabilidad en el mercado. La película objeto del presente estudio "Rio", es una producción de 21th Century Fox proyectada a escala mundial; la cual transporta a la audiencia a la ciudad de Rio de Janeiro.

Las imágenes proyectadas en una película pueden llevar a la generación de un constructo de tipo imaginativo, de creencias, conocimiento y afecto en cuanto a personajes, lugares y culturas, que últimamente han generado una demanda turística (Kim, 2012; Beeton, 2005; Iwashita, 2006; Roesch, 2009). Igualmente, los destinos buscan desarrollar atractivos culturales alternativos relacionados con la cultura popular, festivales y eventos derivados del cine (Rodriguez, Fraiz y González, 2014).

Desde la perspectiva de la imagen de destino, los filmes son fuentes de información no formales que influyen en la construcción de ésta (Gartner, 1993; Baluglu et al., 1999; Echtner y Ritchie, 2003; Tasci y Gartner, 2007) una vez que la información es procesada en la mente de las personas o audiencias, se forma un concepto significativo sobre un destino: sea cognitivo y afectivo, positivo o negativo. Así, las percepciones de las audiencias o potenciales turistas en este estudio representan evaluaciones de tipo cognitivo y afectivo sobre el destino Rio de Janeiro.

Las producciones cinematográficas no solo influyen en las percepciones sino también en las expectativas de potenciales turistas, en relación a que existe 0 se puede hacer en ese destino (Connell, 2012; Beeton, 2005; Kim, 2012). Algunas investigaciones en el campo de turismo cinematográfico han considerado expectativas generadas por diferentes géneros fílmicos. La mayoría de los discursos e investigaciones han asumido que las películas con personajes reales y no animados, son aquellas que tienen un impacto a nivel de percepciones, expectativas y susceptibles de generar turismo; no obstante las películas animadas también tienen exposición importante y muestran destinos, por ejemplo: UP (Monte Roraima - Venezuela), La princesa y el sapo (New Orleans - Estados Unidos), El niño y la bestia (Tokio - Japón), Valiente (Escocia), Una aventura congelada (Noruega), entre otras.

La experiencia de consumir una película puede contribuir a la formación de imaginarios de un destino; esto puede ser percibido por la audiencia como elementos de marketing no inducidos (O'Connor et al., 2010). La industria cinematográfica ha creado escenas "incidentales" que han servido como elementos promocionales, dando lugar al emplazamiento de nuevos productos, como reconoce Hernandez Ramírez (2011), poco o nada tienen relación con la 
historia y cultura del destino, pero actúan como elementos que se incorporan al paisaje cultural del destino. Por ello, desde la perspectiva de los actores turísticos, surge el deseo de investigar y generar estrategias para emplazamiento de lugares o uso efectivo de imágenes y escenas filmográficas.

Butler (2011) sugiere que la influencia de un filme en las audiencias depende de factores clave como género y estilo del director. Kim (2012), profundiza en este análisis y propone que los "valores de producción" tales como música, personajes, narrativa e historia, localización y efectos fílmicos juegan un rol trascendental en la interpretación mental de las audiencias con respecto a un destino. Las películas animadas, en este sentido, presentan valores de producción que llaman la atención. Beeton (2005), sugiere que las películas animadas sean reconocidas e investigadas, debido a las semejanzas con películas no animadas. En 2012 y 2013, el Scotish Tourism Board y el Norwegian Tourism Board en conjunto con Disney-Pixar usaron producciones cinematográficas animadas de emisión mundial, Valiente (2012) y Frozen (2013,) respectivamente para promocionar sus destinos.

De esta manera, una exploración sobre percepciones y expectativas turísticas generadas antes y después de ver la película animada Rio (2011), en relación a la ciudad Rio de Janeiro, es relevante.

Existen limitados estudios vinculados a la imagen del destino Rio de Janeiro y más aún relacionados a los medios como el cine, por ello la presente investigación será un aporte para futuras exploraciones en el ámbito de turismo cinematográfico. Un notable estudio realizado por Rezende-Parker, Morrison e Ismail (2002) entre norteamericanos y su percepción sobre la imagen de Brasil, reveló que ellos lo perciben como un destino con atractivos naturales, atmósfera placentera y única; sin embargo, sienten temor por el crimen y la violencia; no obstante, este estudio no tenía relación con la influencia de los medios ni de un filme animado.

\section{Turismo cinematográfico y perspectivas de investigación}

Existen evidencias mundiales crecientes sobre turistas visitando lugares que aparecen en películas o en televisión (Iwashita, 2007; Connell, 2012; Roesch, 2009; Beeton, 2005; Kim, 2012; Croy, 2010; Soliman, 2011; Hudson and Ritchie, 2005; Connell, 2008; Dung y Reijnders, 2013). Este fenómeno es conocido como turismo cinematográfico. Lo que un turista busca es una experiencia vivencial, eventualmente una única interpretación del material consumido previamente por este medio (Macionis, 2004). "Las audiencias, potenciales turistas, se sienten motivados por curiosidad, diversión, peregrinaje o el deseo de una experiencia en directo" (Kim et al., 2007). Si bien, los productores cinematográficos no siempre buscan atraer turistas, las producciones que se enfocan en destinos específicos proveen oportunidades para aquellos lugares en donde se concibieron y de esta manera pueden ser 
más competitivos en el creciente mercado turístico. Warnick et al. (2005) argumenta que una buena película puede resaltar la belleza de un destino retratado y puede influir efectivamente en la imaginación de las audiencias, especialmente si la narrativa y la localización están interrelacionadas (Beeton, 2005). Reinjnders et al. (2015), sugieren la existencia de una memoria geográfica evolutiva, en donde conforme la influencia de los medios el deseo de descubrimiento en busca de validación crece, eventualmente constituyéndose en un estímulo imaginativo geográfico.

Las discusiones y alcances dentro de la investigación del turismo cinematográfico toman dos diferentes caminos sugeridos por Connell (2012). Uno se enfoca en gestión y marketing, el cual busca determinar las implicaciones, oportunidades y retos de las producciones cinematográficas, además de sus aplicaciones en gestión y generación de estrategias de turismo. El segundo punto de vista se deriva de la perspectiva cultural de los filmes y las razones que estimulan, contribuyen y explican el significado y reacciones de la actividad turística cinematográfica per se. Beeton (2005), concluye que la indagación en turismo cinematográfico puede ser realizada en temas de: motivaciones, tours a lugares de celebridades, nostalgia creada por películas, atracciones construidas, parques temáticos en relación a películas, festivales de cine y experiencias vivenciales cuasi reales. En Japón, el turismo cinematográfico ha sido definido como turismo de contenidos (content tourism kontentsu tsūrizumu) en relación al fenómeno generado a partir de peregrinaciones a "lugares sagrados" que se relacionan a historias, ficciones y narrativas en medios como películas animadas, series de televisión (anime), juegos y revistas (manga), relacionados a la cultura popular de esta nación (Seaton y Yamamura, 2015).

Consecuentemente, el turismo cinematográfico es multidisciplinario y abarca la geografía cultural, producción de medios, psicología, marketing y gestión (Connell, 2012).

\section{El impacto de las películas en las percepciones de audiencias o potenciales turistas}

El sentido común puede sugerirnos que ir al cine a ver una película no tiene relación alguna con el turismo debido a que es poco probable que todas las audiencias que ven un filme se sientan motivadas a viajar al destino retratado, caso contrario el turismo cinematográfico sería ya un turismo de masas. En cambio, las audiencias son consideradas potenciales turistas que quizás un día viajen a un destino por una variedad de razones de entre las cuales puede ser una visita motivada por una película. Urry (2002) argumenta que las películas son ventanas para la contemplación de lugares. Él sugiere que el turismo cinematográfico es una colección de signos, sueños y anticipaciones. Por ejemplo, la película Paris Je táime (2006) es una representación romántica de historias de amor en París, consecuentemente, la percepción idealista 
generada de esa ciudad es relacionada al amor y romance. Dung y Reijnders (2013) examinaron la influencia de películas filmadas en París en la imaginación de turistas chinos, durante su visita a esta ciudad. La percepción romántica prevaleció, pero al mismo tiempo se objetó, al percibir suciedad, diversidad racial y parisinos poco amigables.

Karpovich (2010), comenta acerca del impacto de películas en audiencias, refiriéndose al sentimiento de nostalgia generado por migrantes que vieron a su tierra materna representada en el género italiano Dal-Vero. Este tipo de producciones son realizadas con tomas que representan paisajes de ciudades que generan un sentido de viaje a través de la ciudad. Las películas juegan un rol importante al influir en las emociones humanas mientras dura una película, disparando las motivaciones a visitar, la gente, lugar y cultura que fueron plasmados en la pantalla, factor conocido como "empuje" en turismo. El factor de empuje surge normalmente del atractivo de ese paisaje cultural y las diferentes imágenes en la película (Connell, 2012; Macionis, 2009).

Kim (2012), sugiere que el contenido romántico e idealista de las telenovelas y su efecto por consumo sostenido generan una experiencia vívida. Pues hoy en día el mundo mediático virtual se ha convertido en el medio de referencia para entender al mundo. Urry 2002; Reijnders et al., 2015, sugieren que el individuo post moderno ya no puede distinguir entre lo real y ficticio, debido al consumo de los medios masivos y a pesar de que las películas animadas están hechas mayoritariamente para audiencias infantiles, estas pueden llegar a influir de manera considerable en los adultos. Un estudio realizado por el Scotish Tourism Board en 2012 acerca de las actitudes del consumidor de filmes en Gran Bretaña concluyó que el $75 \%$ de personas mostraba interés en ver películas de animación, el $41 \%$ disfrutaba ver las mismas y el $34 \%$ las vería si se encontraran disponibles (Scotish Tourism Board, 2012). Además, Pikkov (2010) sugiere que una animación proyecta la realidad de manera más objetiva que una producción no animada porque las animaciones pueden capturar la esencia de un tema, representándolo en lugar de reproducirlo.

Frost (2010), propone que la combinación de historias únicas, temas y mitos son clave para potenciar el interés de lugares proyectados en las películas. La combinación de la narrativa y la historia puede influir en la interacción visual, además de proporcionar a las audiencias una promesa de cómo puede ser ese destino y también pueden provocar una profunda reflexión sobre la vida misma en el contexto de animaciones, el director Hayao Miyasaki genera narrativas de profunda reflexión en animaciones como: El viaje de Chihiro (2001), Ponyo (2008), entre otras.

Las películas crean puentes entre culturas lejanas, aumentando el conocimiento de diferentes paisajes culturales (Tasci, 2009). Por ejemplo, películas animadas japonesas podrían generar efectos en audiencias latinoamericanas y generar expectativas y percepciones a través de historias únicas que muestran la auténtica cultura y paisaje japonés. Populares filmes 
como Mulan (1998) y Kung Fu Panda (2008) proyectan el paisaje cultural de China.

Estas animaciones son una premisa para el desarrollo del conocimiento del lugar, ya que representan elementos reales y ficticios. Jewell y McKinnon (2008), creen que las películas tienen la capacidad de generar un nuevo paisaje cultural de un destino y eventualmente convertirse en parte de la identidad del lugar, esto ocurre, por ejemplo, con El Señor de los Anillos (20012003). Estas generaron una identidad única para Nueva Zelanda relacionada con intrincados paisajes naturales y poblados ficticios de Tierra Media.

\section{Géneros cinematográficos y valores de producción: ¿Determinantes del turismo cinematográfico?}

Indiscutiblemente, las características del medio, el turista y el destino motivan al turista, un medio literario, musical y cinematográfico con sus características particulares pueden conmover y sacudir emocionalmente a una persona (Reijnders, 2015). Así, cabe considerar el tema de la diversidad de géneros cinematográficos debido a su ausencia en el discurso del turismo. Se ha asumido que solo las películas tipo "Hollywood" pueden influir en potenciales turistas (Kim, 2011); pero existen otros criterios que bien podrían influir. Soliman (2011), cree que producciones independientes y domésticas han generado turismo local, así el ejemplo de "El capitán Hima" (2008), el cual generó flujo turístico interno por las importantes escenas naturales y románticas de Al-Fayoum en Egipto. Evidencia empírica en series de televisión para niños como "Ballamory" (2002-2005) también han generado turismo familiar y de niños a la Isla de Mull en Escocia (Connell, 2008). Además, telenovelas como "Sonata de Invierno" (2002), han atraído miles de turistas asiáticos a localizaciones en Corea del Sur (Kim, 2010). Bazanes e Ingram (2013), proponen cuatro categorías de películas que podrían generar impacto en el turismo: 1) películas animadas, 2) documentales, 3) películas basadas en hechos reales, 4) películas basadas en novelas, biografías y eventos históricos. De igual manera, Beeton (2005) reconoce la diversidad de géneros en el turismo cinematográfico, que van desde drama, acción, ciencia ficción, guerra y terror.

La animación, es una técnica que sirve para representar un género (Pikkov, 2010). En la actualidad los diseñadores de animación cuentan con tecnología avanzada que resalta historias, embellece primeros planos y fondos, paisajes y entornos. Por lo tanto, las producciones animadas pueden ser usadas efectivamente para emitir mensajes en relación a problemas ambientales como por ejemplo La princesa Mononoke (1997) y Wall-E (2008), que destacan por su temática ecologista. James (2013), comenta que la animación permite romper esquemas de realidad en donde los caracteres conversan entre ellos e incluso objetos pueden ser animados. Pikkov, (2010) asegura que las películas animadas son más interesantes para las audiencias, ya que las historias son 
visualmente originales y al mismo tiempo estas se convierten en mitos. Jewell y McKinnon (2008), argumentan que los mitos pueden guiar acciones y esconder la verdad. Así, las animaciones por más que no sean concebidas reales, pueden desarrollar mitos atractivos en torno a destinos. En conclusión, las animaciones pueden presentar personas, lugares y culturas de una manera original y eventualmente construir una imagen y la imaginación de un destino de manera más efectiva que las películas no animadas.

Croy (2011), resume las posibles razones por las que un filme puede inducir al turismo: entorno físico pintoresco, asociación e interpretación de historias, contenido temático, celebridades, relaciones humanas que pueden ser asociadas con la vida de las personas y actividades novedosas que pueden ser representadas en las películas. Kim (2012), asocia estos criterios bajo la etiqueta de "valores de producción" y argumenta que estos pueden ser elementos que pueden motivar a las audiencias y convertirlos en turistas cinematográficos, estos son: a) narrativa e historia; b) localización; c) celebridades y personajes, d) técnicas visuales y música.

La narrativa y la historia de una película generan un mayor enganche y familiarización con los personajes de la historia (Kim, 2012), de igual manera, la narrativa puede proponer un conocimiento adicional en audiencias en relación a un destino e incluso generar un contexto de anticipación de las posibles atracciones y experiencias.

La localización presentada en una producción puede resultar ser más influyente y eventualmente provocar un deseo de visitar el lugar debido a la representación de paisajes idílicos y espectaculares. Convery et al. (2012), reconocen también que una localización puede destacar la existencia de vida salvaje, arquitectura, valores culturales, tradiciones y costumbres.

Otro valor de producción importante son las celebridades y personajes. Las audiencias están fascinadas por sus actores, actrices favoritas y otros personajes que son vitales en el desarrollo de la empatía con los observadores (Kim, 2012). Últimamente las audiencias son atraídas hacia las localizaciones donde sus caracteres favoritos interactúan. Kim y Richardson (2003), también comentan que una intensa relación entre las audiencias y los personajes de la película puede moldear afecciones del turista hacia un lugar.

En lo concerniente a la tecnología, esta mejora considerablemente la experiencia visual, así las herramientas de filmación y edición pueden ser utilizadas en representaciones que pueden proveer diferentes puntos de vista y formas de expresión artística. Kim (2012), argumenta que la combinación estética visual y técnica puede facilitar el flujo de fantasías, placeres y diversión, generando una experiencia turística "postmoderna" en donde la realidad se desvanece. Este proceso es crucial en las películas animadas que combinan narrativa, personajes, colores y espacios virtuales. 
La música también puede contribuir de manera importante aumentando la experiencia emocional en las películas (Cohen, 2011, citado en Kim, 2012). En efecto, la música tiene un impacto profundo en los sentimientos de las personas y puede generar un sentimiento de nostalgia. En las películas animadas la música es clave para darle vida a toda la creación fílmica.

Bajo toda esta perspectiva, el content tourism Japonés, aporta de manera importante al discurso enfocando su razón de ser a contenidos, narrativa, caracteres y localización, de esta manera, en una etapa avanzada de influencia en las audiencias, se termina produciendo una simbiosis entre el destino, contenidos y los productores de las historias con implicaciones económicas a nivel de turismo importantes (Seaton y Yamamura, 2015).

\section{Imagen de destino y la relación con turismo cinematográfico}

Existen diferentes tipos de comportamiento del consumidor turístico durante tres fases: pre-visita, visita y post-visita (Taschi y Gartner 2007). La fase previsita es crítica porque el turista configura o refuerza expectativas turísticas que fundamentalmente son imaginarias sobre el producto turístico y las posibles experiencias, es aquí en donde se enfocan esfuerzos para comprender y evaluar la imagen de destino.

La imagen de destino se define como un "sistema interactivo de pensamientos, opiniones, sentimientos, visualizaciones e intenciones acerca de un destino" (Tasci et al., 2007). Mckay y Fasenmaier en 1997, definen la imagen de destino como "la compilación de creencias e impresiones basadas en información procesada proveniente de una variedad de fuentes a lo largo del tiempo, resultando en una construcción mental". En otras palabras, representa los atributos de un sitio que una persona tiene en su mente. Comprubí y Coromina (2016), sugieren que la imagen de un destino es forjada a partir de estereotipos generados por fuentes de información que no siempre son fieles a la realidad y surgen de un imaginario colectivo que no es individual, determinando la imagen de un destino a un estereotipo universal. Uno de los consensos importantes entre los actores turísticos es que la comprensión del desarrollo de la imagen de un destino es crucial para el posicionamiento, promoción y éxito del mismo en el mercado turístico (Baloglu y McCleary, 1999; Tasci y Garner, 2007). Más aún, Crompton (1979) y Galarza et al. (2002), sugieren que la imagen es más importante que los atributos físicos, ya que las percepciones en relación a la realidad son las que hacen que las personas reaccionen o no. Evidentemente, la imagen percibida es determinante en el éxito de un destino. Es muy importante establecer tempranamente la formación de la conciencia, percepciones y expectativas acerca de los destinos para comprender las implicaciones y potenciales impactos en el turismo de esos lugares.

Gartner (1993), sugiere tres dimensiones para la imagen de destino: 
- Cognitiva: aquello que los individuos piensan sobre el sitio

- Afectiva: que sienten los individuos con respecto al sitio; y

- Conativa: como los individuos reaccionan con respecto al lugar.

Gartner (1993), and Kim y Yoon (2003) sugieren que estos factores pueden ser estudiados individualmente para comprender su efecto en los individuos y sugiere que los elementos cognitivo, afectivo y conativo están jerárquicamente interrelacionados. Agapito et al (2013) comprobó esta interrelación y sugiere que mientras más positivo sea el elemento afectivo, este tiende a influir de igual manera en la evaluación cognitiva y conativa.

La construcción de la imagen de destino es netamente individual y refleja la imaginación e interpretación a partir de diferentes canales de comunicación. Como ya ha sido mencionado, las películas son fuentes poderosas de construcción de imágenes. Técnicamente, las películas son agentes autónomos o independientes que influyen en la construcción de una imagen de destino (Tasci y Gartner, 2007; Beeton, 2006; Kim, 2012). En efecto, la información visual obtenida de una película puede influir en el comportamiento del consumidor y en variables como deseo de visita e intención de compra. Es esta evaluación de la cognición de los potenciales turistas la que es relevante para las organizaciones gestoras de destinos ya que determinan la reputación de un destino y consecuentemente el interés o viceversa sobre el mismo. Finalmente, estas evaluaciones tengan resultados positivos o negativos son usadas para generar estrategias de marketing orientadas a mejorar u optimizar la imagen de un destino.

\section{Metodología}

Este estudio de caso examina y compara las percepciones de individuos sin previa experiencia de viaje a Rio de Janeiro. El objetivo es determinar como una animación influye en las percepciones y expectativas de potenciales turistas en relación al destino. Así se configuran las siguientes preguntas planteadas en esta investigación:

- ¿Cuáles son las percepciones y expectativas acerca de Rio de Janeiro antes de ver la película Rio?

- ¿Cuáles son las percepciones y expectativas acerca de Rio de Janeiro después de ver la película?

- ¿Hasta qué extensión la película animada Rio influye en las percepciones y expectativas de turistas en relación del destino Rio de Janeiro?

La producción cinematográfica animada Rio ha sido seleccionada para este estudio debido a la interesante representación del paisaje cultural de Rio de Janeiro. Esta es una aventura musical del guacamayo Jacinto (Anodorhynchus hyacinthinus) que intenta descubrir sus raíces en la ciudad maravillosa. La 
película Rio obtuvo el puesto trece en recolección del año 2011, con una recaudación mundial de \$484.635.760 (Box Office Mojo).

Los estudios de caso han sido reconocidos como una estrategia adecuada e importante en turismo, ya que estos realizan un análisis profundo del fenómeno permitiendo la aplicación de diferentes métodos e instrumentos de recolección e interpretación de datos (Smith, 2010). El análisis temático es la principal herramienta usada para comparar los cambios en percepciones de los participantes en relación al destino propuesto, el cual se complementó con análisis inferencial no paramétrico.

La fuente primaria de evidencia para este estudio fueron entrevistas semiestructuradas, las cuales se analizaron bajo un enfoque cualitativo y se complementaron con un análisis inferencial representado por el uso de la prueba no paramétrica denominada "prueba de los signos", la cual es una utilizada para comparar los cambios antes y después de un evento; en este caso, el evento fue presenciar la película Rio. En los casos en que el valor $p \leq 0,05$, se concluyó que existen diferencias estadísticamente significativas entre las apreciaciones antes y después de presenciar la película. Se cuantificaron el número de individuos que manifestaron cambios y los que no presentaron cambios. Se utilizó el programa estadístico SPSS y se consideró un nivel de significación de 0,05.

La metodología cualitativa permite entender los pensamientos de las personas entrevistadas, sus propias experiencias, sus propios conceptos, más no los del investigador (Jennings, 2010). Esta premisa apuntala el contexto de investigación en donde se comprende que los medios configuran las percepciones humanas colectivamente en relación a destinos. En realidad aquello que se busca es una perspectiva intrínseca descrita desde la mente misma de las personas sobre un mundo guiado por los medios masivos. Masson (2002) sugiere que los resultados de la metodología cualitativa permiten interpretaciones argumentadas que configuran perspectivas de como las cosas funcionan en diversos contextos. Adicionalmente, Charon (2004) argumenta que los humanos no sienten el entorno directamente, sino que esto resulta de un proceso mental de interacción y pensamiento.

Esta investigación tomó lugar en la Universidad Flinders en Adelaida, Australia Meridional. Diecinueve participantes de diversas nacionalidades, mayores de 18 años de edad, fueron seleccionados para el estudio. Los participantes fueron entrevistados individualmente bajo condiciones favorables antes de ver la película y posteriormente fueron invitados a participar en la proyección de la película en un auditorio de la universidad, el cual fue arreglado para generar una experiencia como la de un cine. Luego se convocó a los participantes individualmente para la entrevista final.

El criterio usado para la recolección de datos mediante entrevistas semiestructuradas, fue el criterio de "lugar", el cual propone que estos se componen de un entorno social, ambiental y físico, conforme la entrevista desarrolló, se 
plantearon preguntas orientadas a obtener una percepción importante sobre el destino. De esta manera se lograron obtener criterios tangibles e intangibles sobre la ciudad Rio de Janeiro. Se obtuvieron imaginaciones, creencias y conocimientos (componentes cognitivos), afectivos (componentes afectivos) y expectativas. Las entrevistas posteriores fueron configuradas de manera similar, aunque se plantearon preguntas menos estructuradas y más abiertas en búsqueda de un desarrollo de respuestas. La duración promedio de las entrevistas fue de 30 minutos cada una y se utilizó un grabador de voz, las transcripciones de las entrevistas se realizaron inmediatamente de finalizadas.

Se hizo un análisis temático de las transcripciones una vez terminada la recolección de datos, en donde se determinaron las categorías o temas en relación a los componentes cognitivos de la imagen de destino dadas por los entrevistados y fueron los siguientes: problemas sociales y seguridad, paisaje físico, eventos culturales, comida local, comunidad local amigable, recursos naturales, iconos culturales y naturales. También se clasificaron los componentes afectivos en relación al destino en la escala propuesta por Rusell (1980), desagradable-agradable, aburrida-animada, melancólica-excitante, estresante-relajante. Las expectativas fueron comparadas conforme fueron surgiendo luego de la post-entrevista.

En busca de la objetividad de los resultados, se procedió a contabilizar las palabras mencionadas en relación a los subtemas para posteriormente comparar si las frecuencias aumentaban o disminuían y se procedió a llevar a cabo una prueba no paramétrica inferencial considerando solo los elementos naturales, con la finalidad de establecer el impacto de la película en relación a los mismos.

\section{Resultados}

Los temas y subtemas analizados se presentan en el Cuadro 1.

Cuadro 1Temas y subtemas del Análisis Temático

\begin{tabular}{|l|l|}
\hline \multicolumn{1}{|c|}{$\begin{array}{c}\text { Temas y subtemas } \\
\text { seguridad }\end{array}$} & \multicolumn{1}{c|}{ Temas y subtemas } \\
\hline Problemas sociales y & \multicolumn{1}{c|}{ Locales amigables } \\
\hline Priminalidad & Amigables y felices \\
\hline Inseguridad & Buenos anfitriones \\
\hline Riesgo & Gente genial \\
\hline Narcotráfico & Buena fiesta \\
\hline Pobreza & Gente sexy \\
\hline Prostitución & Recursos naturales \\
\hline Abuso infantil & Diversidad de aves \\
\hline \multicolumn{1}{|c|}{ Ambiente físico } & Vida salvaje \\
\hline Montañas verdes & Áreas protegidas \\
\hline
\end{tabular}




\begin{tabular}{|c|c|}
\hline & Amazonas \\
\hline Paisaje montañoso & $\begin{array}{l}\text { Tráfico ilegal de } \\
\text { animales }\end{array}$ \\
\hline Playas & $\begin{array}{c}\text { Iconos naturales y } \\
\text { culturales }\end{array}$ \\
\hline Selva cercana & Cristo Redentor \\
\hline Ciudad costera & Carnaval \\
\hline $\begin{array}{c}\text { Manifestaciones } \\
\text { culturales }\end{array}$ & Fútbol \\
\hline Patrimonio portugués & Teleférico \\
\hline Cultura aborigen & Tranvía \\
\hline Carnaval & Guacamayo azul \\
\hline Fútbol & Favelas \\
\hline Música y danza & Componente afectivo \\
\hline Religión & Compasión \\
\hline Gastronomía & Felicidad \\
\hline Gastronomía local & Terror \\
\hline Comida con frejol & Vibrante \\
\hline Estilo mexicano & Interesante \\
\hline Comida única y exótica & Agradable \\
\hline Parrillada & Negativo \\
\hline Corazones de pollo & Excitante \\
\hline
\end{tabular}

\section{Problemas sociales y seguridad}

La paz, estabilidad y seguridad de un destino son sensibles para el mercado de turistas, ya que determina la posibilidad de escoger un destino. En este caso, los potenciales turistas entrevistados, antes de ver la película percibían a Rio de Janeiro insegura y con problemas de gobierno, sin embargo la percepción de inseguridad disminuyó después de visualizar la película, al igual que los problemas de gobierno. Aunque la película Rio presenta la pobreza de las favelas y el abuso infantil, entre otros problemas sociales, los cuales influyeron en los comentarios de los turistas, ellos aún percibían Rio de Janeiro como un destino atractivo. Uno de los comentarios más relevantes al respecto dice:

“...mi percepción sobre Rio de Janeiro ahora es mejor, debido a la combinación de colores, música y personajes. Aunque se puede ver el lado oscuro de las favelas y los problemas sociales. Para mí la película ayudó a mejorar mi idea sobre Rio"

Tasci (2009), menciona que las imágenes positivas de un destino, pueden reducir considerablemente las preconcepciones y sesgos sobre el mismo. De igual manera, las representaciones cinematográficas pueden generar conciencia sobre problemas sociales y ambientales y eventualmente provocar un deseo de realizar turismo en favor de la conservación y ayuda a los pobres.

\section{Ambiente Físico}


Las percepciones en relación al ambiente físico de Rio de Janeiro se establecieron, fortalecieron y cambiaron durante la pre-post evaluación, debido al énfasis en la representación del increíble paisaje de Rio de Janeiro. Croy (2011) argumenta que escenas pintorescas sobre ambientes físicos puede contribuir a mejorar la imagen de un destino. Dentro de los temas más significativos, en el cual es evidente el establecimiento de percepciones, es el de la idea de un espacio selvático en las inmediaciones de Rio de Janeiro. Así uno de los comentarios al respecto dice:

“...lo único que no me esperaba de Rio de Janeiro era la existencia de una frondosa jungla y la diversidad de flora y fauna en ella. No sabía que existía una selva tan cerca a la ciudad".

En realidad, el espacio selvático más cercano a Rio de Janeiro se encuentra a una hora de viaje desde la ciudad y está contemplado por el bosque de Tijuca.

\section{Manifestaciones Culturales}

Las imágenes de Rio de Janeiro en relación a manifestaciones culturales fueron reforzadas, sobre todo en relación al Carnaval de Rio, el cual es uno de los eventos más importantes a nivel mundial. La producción animada puede ser un elemento que puede ayudar al posicionamiento y promoción del Carnaval. Este es un elemento icónico que es una muestra auténtica de la cultura Brasileña. El gusto por el fútbol y la música también fueron mencionados de igual manera antes y después de la intervención de la película. Uno de los participantes comentó:

“...creo que se confirmó que los brasileños están siempre prestos al baile y a jugar futbol"

Las manifestaciones culturales son de gran importancia en el turismo y ha quedado comprobado que una película animada puede ser un elemento que refuerce y resalte estos eventos.

\section{Gastronomía}

Las percepciones en relación a la gastronomía brasileña fueron desconocidas antes e incluso después de la película. Si bien existe una escena en donde se destaca la gastronomía local, no hubo un impacto relevante al respecto. Cabe resaltar, en este sentido, que el comentario general en relación a la gastronomía fue de exótica y única.

\section{Locales amigables}

El análisis temático en relación a las percepciones sobre las habitantes de Rio de Janeiro, indica que los brasileños destacan por la alegría y por ser buenos anfitriones. Estas percepciones son importantes y la película confirmó lo mismo y es un elemento que puede influir mayoritariamente en una decisión de viaje. Kim (2012), sugiere que los filmes tienen la habilidad de presentar modales de culturas y estilos de vida, lo cual forma una idea de cómo es la gente y cultura 
de un destino. Una percepción de este tipo hace un destino altamente atractivo. Un participante comenta:

“...es más algo sobre la gente y la atmosfera que me atrae a Rio. Me parece que la gente hace la atmosfera y eso es muy positivo en Rio, la gente es muy alegre y eso me hace desear ir"

\section{Recursos naturales}

El análisis de datos en relación a los recursos naturales de Rio de Janeiro de acuerdo a este estudio fue de los más significativos. Las percepciones previas en relación a los mismos fueron bastante limitadas, esto cambió con ver la película y lograron percibir a Rio de Janeiro como un destino con una riqueza natural importante, destacando lo atractivo de la ciudad con una selva cercana, con diversidad de aves y rodeada de verdes montañas. Si bien en la realidad la diversidad de aves es cuestionable, las películas pueden ayudar a crear mitos y estar presentes en la mente de las audiencias, aumentando las oportunidades para los destinos. La película presentó una problemática en relación al tráfico de especies exóticas, si bien esto puede ser un elemento negativo para el destino, la narrativa de la película y el desenlace de la historia sugieren que existe una problemática y una solución, esto puede ayudar a crear consciencia y un deseo de colaborar en favor de la conservación de especies.

\section{Iconos naturales y culturales}

Durante el estudio, las percepciones de los turistas en relación a los monumentos o íconos de Rio de Janeiro fueron diversas. Si bien, la gran mayoría de los participantes comentó sobre el Cristo Redentor, el fútbol y las favelas; existieron íconos que emergieron luego de la película, como fueron: el tranvía de Santa Teresa y el guacamayo azul, los cuales fueron ampliamente comentados.

\section{Componentes afectivos}

Las respuestas afectivas en relación al destino Rio de Janeiro, fueron en algunos casos, sentimientos de miedo frente al destino por los problemas de inseguridad existentes, al igual de un sentimiento de alegría por lo vivaz del destino. La película propició un campo para el desarrollo de emociones diversas, en donde la narrativa influyó considerablemente. Existieron sentimientos de tristeza por la representación de un niño huérfano y al mismo tiempo de alegría por la ilustración del carnaval de Rio de Janeiro y el desenlace de la historia. Beeton (2005), al igual que Kim y Richardson (2003), comentan que potenciales turistas construyen conocimientos y paralelamente desarrollan sentimientos hacia un destino en base a narrativas con carga emocional. 


\section{Expectativas turísticas}

En cuanto a las expectativas turísticas percibidas y posteriormente desarrolladas, se ha identificado que hubo una alta influencia de las imágenes cinematográficas. Inicialmente los participantes en la investigación no tenían muy clara la idea de las actividades que se podían realizar en el destino Rio de Janeiro; sin embargo, la película mostró actividades como: parapente, observación de aves, visita a la selva y dar un paseo en tranvía. Urry (2002), comenta que las audiencias de películas son absorbidas por un estado onírico que desarrolla anticipaciones. Más aún, Frost (2010), sugiere que los atributos de la representación proveen una promesa de cómo pueden ser las posibles experiencias de turistas en los destinos. Las expectativas turísticas son clave para que los destinos se preparen en ofertar aquellas actividades que eventualmente han sido proyectadas en películas.

\section{Análisis inferencial}

De acuerdo a los resultados expuestos en el Cuadro 2 relacionados al entorno natural de la ciudad de Rio de Janeiro y a través del uso de la prueba de los signos; se aprecia que existen diferencias significativas en las apreciaciones de las personas encuestadas después de ver la película en los siguientes ítems:

1) Cantidad de encuestados que notaron la presencia de colinas y áreas verdes para disfrutar y realizar turismo, en la ciudad de Rio de Janeiro. Antes de visualizar la película fue $10,5 \%$ y posteriormente $52,6 \%$ la diferencia entre el antes y después fue estadísticamente significativa $(p=0,0193)$

2) Mayor cantidad de encuestados (63,1\%) expresaron la existencia de especies únicas de aves en la ciudad de Rio de Janeiro, después de ver la película. La prueba de signos presentó un valor $\mathrm{p}=0,0017$.

3) Alto porcentaje de los encuestados manifestaron cambios después de ver la película relacionados con la presencia de bellos escenarios en la ciudad de Rio de Janeiro $(68,4 \%)$ con un valor $p$ en la prueba de los signos (antes y después) igual a 0,0037.

4) Un $78 \%$ de los encuestaron apreciaron la presencia de bosques cerca en la ciudad de Rio de Janeiro con un valor $p=0,0000$ lo cual marca una diferencia estadísticamente significativa en el antes y después de ver la película. Es de resaltar que antes de ver la película ninguno de los encuestados mencionó este ítem.

En relación a la presencia de parques y plazas, así como también del clima tropical, no hubo diferencias entre el antes y después de ver la película: principalmente porque ya conocían la existencia de estos ítems antes de ver la película; por lo tanto no hubo cambios apreciables. 


\section{Cuadro 2 Análisis inferencial de subtemas relacionados con el entorno natural de Rio de Janeiro}

\begin{tabular}{|c|c|c|c|c|c|}
\hline Subtemas & $\begin{array}{c}\mathrm{N}^{\circ} \text { de } \\
\text { encuestado } \\
\text { s que } \\
\text { apreciaron } \\
\text { este ítem } \\
\text { antes de ver } \\
\text { la película } \\
(\%)\end{array}$ & $\begin{array}{c}\mathrm{N}^{\circ} \text { de } \\
\text { encuestados } \\
\text { que apreciaron } \\
\text { este ítem } \\
\text { después de } \\
\text { ver la película } \\
(\%)\end{array}$ & $\begin{array}{c}\mathrm{N}^{\circ} \text { de } \\
\text { encuestado } \\
\text { s que no } \\
\text { apreciaron } \\
\text { cambios (\%) }\end{array}$ & $\begin{array}{c}\text { Valor } \\
\mathrm{p}\end{array}$ & Sig \\
\hline $\begin{array}{c}\text { Colinas, áreas } \\
\text { verdes }\end{array}$ & $2(10,5)$ & $10(52,6)$ & $7(26,3)$ & $\begin{array}{c}0,019 \\
3\end{array}$ & $\mathrm{SI}$ \\
\hline $\begin{array}{c}\text { Especies únicas de } \\
\text { aves }\end{array}$ & $1(5,3)$ & $12(63,1)$ & $6(31,5)$ & $\begin{array}{c}0,001 \\
7\end{array}$ & $\mathrm{SI}$ \\
\hline Bellos escenarios & $2(10,5)$ & $13(68,4)$ & $4(21,0)$ & $\begin{array}{c}0,003 \\
7\end{array}$ & $\mathrm{SI}$ \\
\hline Selva cercana & $0(0)$ & $15(78,9)$ & $4(21,0)$ & $\begin{array}{c}0,000 \\
0\end{array}$ & $\mathrm{SI}$ \\
\hline Parques y Plazas & $3(15,7)$ & $2(10,5)$ & $14(73,6)$ & $\begin{array}{c}0,500 \\
0\end{array}$ & $\mathrm{NO}$ \\
\hline Clima tropical & $0(0)$ & $4(21,0)$ & $15(78,9)$ & $\begin{array}{c}0,062 \\
5\end{array}$ & $\mathrm{NO}$ \\
\hline
\end{tabular}

\section{Discusión y conclusiones}

Se encontró que la película Rio cambió las percepciones de las audiencias en relación a Rio de Janeiro. Las creencias, conocimientos y afecciones fueron confirmadas o cambiaron por influencia de la película. La representación del paisaje cultural de Rio de Janeiro además de los efectos de la animación y valores de producción influyeron en mencionados ámbitos y en expectativas del potencial turista. Se sugiere que las imágenes, así como los íconos y actividades representadas en la película pueden permanecer en la mente del individuo por un tiempo considerable y seguramente tendrán una profunda influencia en la construcción individual de la imagen del destino Rio de Janeiro. Por ejemplo, la idea de que la ciudad tiene una selva cercana con una diversidad de aves importante en donde existe un guacamayo azul está entre las más importantes. Si bien la pobreza y la criminalidad fueron reportados, los análisis sugieren que posterior a la película estas percepciones disminuyeron, siendo un punto relevante.

La producción cinematográfica es altamente importante en la etapa de pre-vista de Rio de Janeiro, ya que ha desarrollado un sentido de mayor seguridad en relación a que esperar y que hacer en el destino. Rio desarrolló percepciones en relación a ser un destino amigable con el turista, colorido, ciudad con buena atmósfera y gastronomía interesante. Los sentimientos generales hacia el destino fueron siempre positivos antes y después, cabe recalcar que la película 
disminuyó la sensación de un destino desagradable, sin embargo, el indicador de una ciudad insegura se mantuvo.

Desde la perspectiva de turismo cinematográfico, se deduce que las animaciones que representan destinos pueden influir en percepciones y por ende en la imagen de un destino. Se ha demostrado que personas sin previa experiencia cambiaron sus percepciones negativas, su conocimiento previo se reforzó y últimamente generaron expectativas. Es por eso que los gestores de turismo deben usar este tipo de información para mejorar la posición y promoción del destino mediante una animación.

Los resultados de este estudio son una oportunidad para comentar acerca de la metodología utilizada. Por una parte este estudio utilizó una variable que no había sido tomada en cuenta como son las películas animadas, propuso una metodología cualitativa y un análisis inferencial. También, se ha incorporado al escrutinio del turismo cinematográfico, temas en relación a género y valores de producción. Cabe reconocer que si bien la animación no es un género, es una técnica que es atractiva para condensar aventuras, comedias musicales que encantan a familias y sobretodo realzan la belleza de un destino y su paisaje cultural.

Se recomienda que los organizadores de turismo de Rio de Janeiro utilicen los resultados de esta investigación para desarrollar campañas de marketing en relación a la película. También puede ser usada en consolidar la imagen de Rio de Janeiro aprovechando el éxito y difusión de la película animada. Adicionalmente, se debe considerar la relevancia alcanzada por el personaje principal de la película el cual puede ser usado como ícono de la ciudad en el desarrollo de una marca turística. De igual manera el concepto de una selva cercana puede ser explotado como un concepto de una ciudad con mucha naturaleza y la importancia de conservación de especies animales exóticas. También se recomienda el desarrollo de mapas de la película y un trabajo para desarrollar productos en relación a la misma. Las estrategias también deben orientarse a los niños quienes pueden verse influidos para motivar futuras visitas.

Si bien han existido conclusiones y recomendaciones relevantes, se reconocen que el comportamiento de un potencial turista es mucho más complejo, así, las características personales del individuo como valores e intereses no han sido evaluados. De igual manera, la película animada no ha sido analizada como tal, se sugiere un análisis detallado en relación a los valores de producción de la película misma y su influencia en el turismo. Este estudio ha tenido un enfoque en etapas pre-visita, resultaría interesante analizar las percepciones de turistas post-visita. Adicionalmente, la imagen proyectada por la película Rio puede ser usada para entender las implicaciones en la comunidad local. Finalmente, se recomienda profundizar en estudios con animaciones que representen otros lugares y el uso de metodologías estadísticas cuantitativas que permitan el uso de métodos paramétricos, los cuales son de mayor potencia. 


\section{Referencias Bibliográficas}

Baloglu, S. y McCleary, K. (1999). A model of destination image formation. Annals of Tourism Research, 26(4), 868-897.

Beeton, S. (2005). Film Induced Tourism. United Kingdom: Channel View Publications.

Butler, R. (2011). It's only make believe: The implications of fictional and authentic locations in films. Worldwide Hospitality and Tourism Themes, 3(2), 91-101.

Charon, J. M. (2010). Symbolic interactionism. An introduction, an interpretation, an integration. (10th ed.), Boston: Prentice Hall.

Camprubí, R., Coromina, L. (2016). La influencia de las fuentes de información en la formación de la imagen turística. Revista de Turismo y Patrimonio Cultural Pasos. 14(4), 781-796

Connell, J. (2008). 'What's the Story in Balamory?' The impacts of a children's TV programme on small tourism enterprises on the Isle of Mull, Scotland. Journal of Sustainable Tourism. 13(3), 228-255.

Connell, J. (2012). Film tourism - evolution, progress and prospects. Tourism Management, 33, 1007-1029.

Convery, I., Corsane, G., Davis, P. (2012). Making Sense of Place. Multidisciplinary Perspectives. Woodbridge, Suffolk, UK, Rochester, NY: Boydell Press (Heritage matters, v. 7).

Croy, W. G. (2010). Planning for film tourism: Active destination image management. Tourism and Hospitality Planning y Development, 7(1), 21-30.

Dung, Y.-A. O. y Reijnders, S. (2013). Paris offscreen: Chinese tourists in cinematic Paris. Tourist Studies, 13(3), 287-303.

Frost, W. (2010). Life changing experiences. Film and tourism in the Australian Outback. Annals of Tourism Research, 37(3), 707-726.

Gartner, W. C. (1993). Image formation process. Journal of Travel y Tourism Marketing, (2(2/3)), 191-215.

Hall, S. (1997). Representations. Cultural Representations and Signifying Practices. London, Thousand Oaks: Sage in association with the Open University.

Hudson, S. y Ritchie, B. (2006). Film tourism and destination marketing: The case of Captain Corelli's Mandolin. Journal of Vacation Marketing, 12(3), 256-268.

Iwashita, C. (2008). Roles of films and television dramas in international tourism: The case of Japanese tourists to the UK. Journal of Travel $y$ Tourism Marketing, 24(2-3), 139-151. 
James, C. (2013) The Films of Pixar Animation Studio. US: Kamera Books. Jennings, G. (2010). Tourism Research. (2nd ed.), Milton, Qld: John Wiley y Sons.

Jewell, B. y McKinnon, S. (2008). Movie tourism - a new form of cultural landscape. Journal of Travel y Tourism Marketing 24(2-3), 153-162.

Karpovich, A. (2010). Theoretical approaches to film-motivated tourism. Tourism Planning and Development, 7(1), 7-20.

Kim, H. y Richardson, S. (2003). Motion pictures' impacts on destination images. Annals of Tourism Research, 30(1), 216-237.

Kim, S. y Long, P. (2012). Touring TV soap operas: Genre in film tourism research. Tourist Studies, 12(2), 173-185.

Kim, S. (2010). Extraordinary experience: Re-enacting and photographing at screen tourism locations. Tourism and Hospitality Planning $y$ Development, 7(1), 59-75.

Kim, S. (2012). Audience involvement and film tourism experiences: Emotional places, emotional experiences. Tourism Management, (33), 387-396.

Kim, S. (2012). The Production and Consumption of Screen Tourism Experience. The OR A? Case Study of Asian Audience's Responses to Hallyu and Korean TV Dramas. Germany: Lambert.

Macionis, N. (Ed.) (2004). Understanding the film-induced tourist. Proceedings of the International Tourism and Media Conference. With the assistance of W. Frost, G. Croy, S. Beeton. 88-97. Melbourne, Australia.

Masson, J. (2002). Qualitative Researching. UK: SAGE Publications.

McKay, K. J. y Fasenmaier, D. R. (1997). Pictorial elements of destination image formation. Annals of Tourism Research, 24(3), 537-565.

O'Connor, N., Flanagan, S., Gilbert, D. (2010). The use of film in re-imaging a tourism destination: A case study of Yorkshire, UK. Journal of Vacation Marketing, 16(1), 61-74.

O'Connor, N. y Kim, S. (2014). Pictures and prose: exploring the impact of literary and film tourism. Journal of Tourism and Cultural Change, 12(1), $1-17$.

O'Connor, N. (2011). How can the film-induced tourism phenomenon be sustainably managed? Worldwide Hospitality and Tourism Themes, 3(2), 87-90.

Reijnders, S., Bolderman, L. Van Es, N. Waysdorf, A. (2015). Locating Imagination: An Interdisciplinary Perspective on Literary, Film and Music Tourism. Tourism Analysis, 20, 333-339. 
Rezende-Parker, Morrison, A., Ismail, J. (2003) Dazed and confused? An exploratory study of the image of Brazil as a travel destination. Journal of Vacation Marketing, 9(3), 243-259.

Rodriguez, L., Fraiz, J., Gonzalez, E. (2014). El turismo cinematográfico como tipología emergente del turismo cultural. Revista de Turismo y Patrimonio Cultural Pasos, 12 (1), 159-171.

Pikkov, U. (2010). Animasophy. Theoretical on the Animated Films: Estonian Academy of Arts.

Roesch, S. (2009). The Experience of Film Location Tourists. UK: Channel View Publications.

Schofield, P. (1996). Cinematographic images of a city. Tourism Management, 17(5), 333-340.

Seaton, P. y Yamamura, T. (2015). Japanese Popular Culture and Contents Tourism - Introduction. Japan Forum. 27(1) 1-11.

Smith, S. L. J. (2010). Practical Tourism Research. Wallingford, Oxfordshire, UK, Cambridge, MA: CABI International (CABI tourism texts).

Tasci, A. D. A. y Gartner, W. C. (2007). Destination image and its functional relationships. Journal of Travel Research, 45(4), 413-425.

Tasci, A. D. A. (2008). Social distance: The missing link in the loop of movies, destination image, and tourist behavior? Journal of Travel Research, 47(4), 494-507. 